\title{
Carlos Eduardo Francischone
}

Falar sobre o Prof. Dr. CARLOS EDUARDO FRANCISCHONE é muito agradável e até fácil, porque sempre há alguma coisa a dizer sobre quem trabalha demais. O Prof. ADO, como o chamamos, começou cedo em nossa escola; formado em 1971, já iniciou atividades docentes no ano seguinte, um privilégio para o nosso departamento. Cursar mestrado e doutorado no meio de tantas atribuições, como professor, pesquisador, administrador, cirurgião-dentista, fizeram com que progredisse rápida e conscientemente, passando a uma colaboração presencial e indispensável às disciplinas de Dentistica, sempre com a filosofia que tem caracterizado o nosso ensino: integração clínica com especialidades afins (Prótese, Periodontia, Materiais Dentários e Endodontia). Importante também salientar sua diversificação posterior para a Implantologia, onde atua efetivamente junto à graduação, mestrado e Brånemark Center, da Universidade do Sagrado Coração.

É um dos professores mais conceituados da FOB e de nossa Bauru, solicitado inclusive por comunidades de diferentes regiões do Brasil e do exterior. É talvez hoje o profissional mais completo e eclético de nosso país. Sabe tudo de clínica odontológica, faz e ensina bem tanto planejamento de tratamento como oclusão, cirurgias periodontais, condutas endodônticas, restaurações estéticas, de amálgama, metálicas fundidas, coroas e facetas de porcelana, enfim, suas mãos e percepção visual envolvem como uma redoma a Odontologia.

Conseguiu também aliar valores de vida e de profissão, com demonstrações constantes de apoio, lealdade, respeito, espírito de equipe e, principalmente, amizade. Admiramos o Prof. ADO pelo seu carinho e interesse com a família e com todos que o cercam, entre estes, a equipe da Dentística da FOB-USP.

Dr. José Mondelli

Professor Titular, Chefe do Departamento de Dentistica,

Endodontia e Materiais Dentários da

Faculdade de Odontologia de Bauru,

Universidade de São Paulo

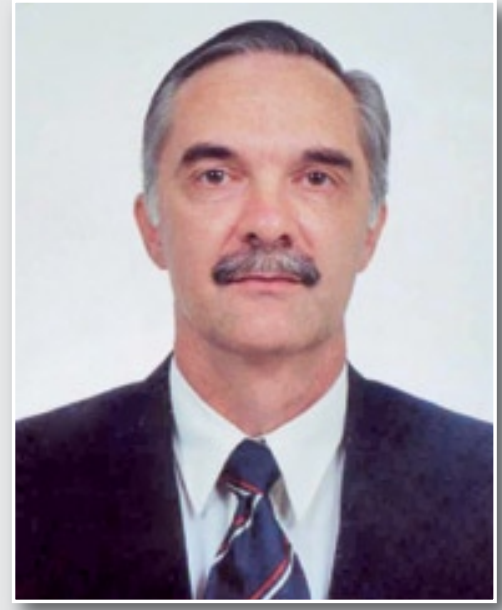

- Professor Titular do departamento de Dentistica, Materiais Dentários e Endodontia - FOB-USP;

Professor Titular das disciplinas de Implantologia e Dentística - USC - Bauru;

- Diretor do Brånemark Osseointegration Center - USC - Bauru;

- Coordenador do Curso de Pós-Graduação, Mestrado em Implantologia - USC - Bauru.
1) Diante da reconhecida excelência do Sr., tanto como professor, como pesquisador e clínico reabilitador, o que a sua experiência clínica mais o ensinou, com respeito às reabilitações envolvendo implantes na região anterior do arco (tanto superior quanto inferior)? Conselho editorial

O respeito ao paciente. Dada a alta complexicidade que envolve a reabilitação de pacientes através da osseointegração, bem como as várias alternativas de tratamento e de procedimentos, é fundamental o esclarecimento realístico do paciente a respeito das condutas e dos resultados finais possiveis de serem obtidos. Ao longo de minha vida como professor universitário, pesquisador e clínico que sempre fui, o conhecimento acumulado ao longo desses 35 anos de vida profissional me permite afirmar que os melhores resultados a serem obtidos com um tratamento reabilitador dependem fundamentalmente do planejamento e plano de tratamento corretos.

O planejamento envolvendo a osseointegração é sempre muito complexo nos diferentes níveis de tratamento (desde os desdentados totais a parciais ou unitários) e requer conhecimento amplo da Odontologia. Seguramente a especialidade Implantologia é a mais interdependente de várias outras especialidades odontológicas, a ponto de, 
para um planejamento e tratamento, haver a necessidade de envolvimento multi e interdisciplinar. Este fato se torna mais freqüente e ímperativo quando a reabilitação envolve a região anterior, onde a estética é ponto de maior desafio.

2) Quanto ao uso do implante para reabilitar o incisivo superior lateral, quais os avanços envolvidos na melhor qualidade estética e de manutenção de tecidos periimplantares? Conselho editorial

Especialmente quando há envolvimento estético nas reabilitações com implantes, o planejamento reverso é fundamental na previsibilidade e na adoção de procedimentos ortodônticos, cirúrgicos e periodontais associados à instalação de implantes, em diferentes fases do tratamento. Especificamente na área de incisivos laterais superiores o planejamento multi e interdisciplinar é que vai orientar o tratamento para resultados funcionais e estéticos mais previsíveis e satisfatórios.

$\mathrm{Na}$ presença de agenesia dos incisivos laterais superiores, existem muitos fatores a serem analisados para decidir entre deixar os caninos ocuparem os espaços dos incisivos laterais, modificando sua forma, ou repor sua ausência através da instalação de um implante ou até colocação de prótese adesiva ou fixa convencional.

Um aspecto que deve sempre ser explicado ao paciente é que quando se abre espaço entre o incisivo central e o canino, para tornar possível a instalação de implantes, há quase sempre a necessidade de reanatomizar o osso daquela região através da colocação de enxerto ósseo autógeno.

Esse esclarecimento prévio ao paciente se torna importante pois envolve a integração multidisciplinar, mais tempo de tratamento, riscos, custos e previsibilidade final da estética.

3) Tanto nos casos de reabilitação apenas protética, como naqueles sobre implante, como o Sr. percebe a influência dos guias caninos (e anterior) sobre a qualidade funcio- nal (eventuais dores), de estabilidade (quebras e reparos) e estética em longo prazo? Conselho editorial

É fundamental tanto o guia canino como anterior estarem presentes em todo tratamento reabilitador, seja ele convencional ou através da osseointegração. A proteção mútua entre o seguimento anterior e posterior da boca é o elemento de equilíbrio para o bom funcionamento do sistema estomatognático. Para manter o equilíbrio, a longevidade e o conforto dos pacientes há de se observar alguns requisitos que nós convencionamos denominar "ADO'S FACTOR", os quais serão comentados durante nosso curso em setembro de 2006, na cidade de Maringá/PR. Na reabilitação com implantes o "ADO'S FACTOR “ é conceituado como Adjusting of Dimension and Distribution of the Occlusal Stress and Strain (by P.I. Brånemark, 2005), ou seja, ajustando a dimensão e distribuição das tensões oclusais e sua dissipação para a interface osseointegrada e tecido ósseo subjacente.

\section{4) Quais são as atividades e objetivos do Instituto Brånemark? O Sr. poderia nos fazer uma apresentação deste Centro de Estudos da Osseointegração? Conselho editorial}

O Instituto P.I. Brånemark, sediado na cidade de Bauru, é uma entidade que visa a reabilitação de pacientes com mutilações intrabucais ou da face. Pelo seu caráter social, seu objetivo principal é o atendimento de pacientes com limitações financeiras ou carentes. O professor Brånemark, que é presidente do P.I. Brånemark Institute, sempre se mostrou motivado em possibilitar a reabilitação desses pacientes mutilados e também devolver a auto-estima, o convívio familiar e em sociedade. Isto tornou-se possível com a inauguração do seu instituto, em setembro de 2005. O instituto também terá como objetivo a organização de cursos e eventos para profissionais que desejam se aprimorar em osseointegração e tomar conhecimento de novas tecnologias e procedimentos para poderem reabilitar seus pacientes. 